\title{
LA FORMACIÓN DE GOBIERNOS EN SISTEMAS MULTIPARTIDISTAS: LA PARADOJA DEL CASO ESPAÑOL*
}

\author{
IRENE DELGADO SOTILLOS \\ Catedrática de Ciencia Política y de la Administración \\ Universidad Nacional de Educación a Distancia
}

TRC, núm. 45, 2020, pp. 261-290

ISSN 1139-5583

\begin{abstract}
SUMARIO
I. Introducción. II. Líneas de estudio de los gobiernos de coalición. III. La gobernabilidad en España. IV. La atomización parlamentaria del período 2015-2019. V. ¿Cómo asegurar la gobernabilidad?
\end{abstract}

\section{INTRODUCCIÓN}

En la mayoría de las democracias occidentales, las elecciones no deciden quien gobernará. La configuración de la asamblea legislativa es la pieza determinante de elección de los gobernantes en los sistemas parlamentarios. La hegemonía de un solo partido facilita esta elección, pero cuando no se obtienen unos mínimos necesarios, quien gobernará se decide tras las negociaciones entre los grupos políticos con representación en la cámara legislativa ${ }^{1}$. Una mirada a los sistemas políticos de nuestro entorno ofrece elementos para afirmar que la mayoría de los países democráticos han sido gobernados, en distintos momentos, por coaliciones, son los casos de Alemania, Austria, Bélgica, Dinamarca, Italia,

* Este trabajo se enmarca en el Proyecto de Investigación DER2017-84733-R, Partidos políticos: origen, función y revisión de su estatuto constitucional, financiado por el Ministerio de Economía y Competitividad/ FEDER (Investigadores principales: M. SALVADOR y R. MORÁN).

1 Luebber, G. M., Comparative democracy: policy making and governing coalitions in Europe and Israel, Nueva York, Columbia University Press, 1986. 
Noruega, Países Bajos, Suecia o Suiza ${ }^{2}$. Y aún más, recientemente se aprecia un incremento en el número de gobiernos minoritarios como consecuencia de una epidemia de fragmentación parlamentaria que afecta al continente europeo.

En este contexto, España ha sido hasta recientemente el único país de la Europa continental en el que ninguno de sus gobiernos ha sido formado por más de un partido, consecuencia de un sistema de partidos estable que ha facilitado la gobernabilidad a lo largo de media década, incluso a gobiernos minoritarios ${ }^{3}$. Pero este panorama se ha modificado sustancialmente con la profunda transformación acaecida en el sistema de partidos en años recientes. La elevada fragmentación parlamentaria, resultante de procesos electorales en los que la dispersión del voto entre actores ha comportado que ningún partido disponga de una mayoría absoluta, ha conducido a una situación de parálisis institucional y a un bloqueo gubernamental sin precedentes en la historia democrática de nuestro país. Hoy, parece haberse cerrado un ciclo político que justifica el interés por comprender el comportamiento de los partidos políticos en un nuevo contexto dominado por la incertidumbre política y por nuevos modelos de gobernabilidad.

Guiados por el interés de analizar la excepcionalidad del caso español, este artículo explora los gobiernos multipartidistas o de coalición en el entorno europeo y el marco teórico que arropa a las investigaciones sobre coaliciones, para tratar de analizar la singularidad de nuestro país en la formación de este tipo de gobiernos. La falta de ejecutivos multipartidistas en la esfera nacional se debe a la pacífica coexistencia en la institución parlamentaria de un partido estatal predominante junto con partidos políticos de ámbito no estatal (PANE) de menor tamaño. Estos han sostenido gobiernos minoritarios tras negociaciones bilaterales en las que los actores implicados han obtenido mutuos beneficios. El actual gobierno de coalición se gesta por la debilidad parlamentaria de los partidos estatales lo que exige ya no sólo de PANE para alcanzar acuerdos de gobierno sino también de otras fuerzas de ámbito estatal dispersando la distribución de beneficios en negociaciones multilaterales. La fragmentación del sistema de partidos altera la aritmética parlamentaria e incrementa el número de partidos que ocupan un lugar central en las negociaciones, lo que hace más complejo el proceso de adopción de acuerdos. En este trabajo examinamos las claves explicativas de la formación de gobiernos minoritarios y del primer gobierno de coalición en España centrando el interés en la vinculación establecida entre proceso negociador, asignación de beneficios y estabilidad gubernamental.

2 Nos referimos únicamente a sistemas parlamentarios, dado que la dinámica de los sistemas presidencialistas dista significativamente de los aspectos que se abordan en este trabajo. Para un estudio sistemático y actualizado del contexto presidencialista remitimos al trabajo de CHAsQueTTI, D., «Democracia, multipartidismo y coaliciones en América Latina: evaluando la difícil combinación», en LANZAro, J. (comp.), Tipos de presidencialismo y coaliciones políticas en América Latina, CLACSO, Buenos Aires, 2019, pp. 319-359.

3 Lane, J. y Ersson, S. O., Política europea: una introducción, Istmo, Madrid, 1998. 


\section{LÍNEAS DE ESTUDIO DE LOS GOBIERNOS DE COALICIÓN}

En contextos parlamentarios fragmentados, la formación de gobiernos es un aspecto de singular importancia para el funcionamiento del sistema democrático. Las opciones que se abren basculan entre gobiernos minoritarios con debilidad para afrontar la adopción de acuerdos en el seno de las asambleas parlamentarias, o gobiernos multipartidistas o de coalición que alcanzan la mayoría parlamentaria y dotan de estabilidad al sistema. En este juego de equilibrios políticos, los detractores de los gobiernos minoritarios destacan de ellos un conjunto de efectos perversos tales como la generación de altos niveles de inestabilidad política, el desafío de negociaciones interpartidistas complejas y crisis políticas que conducen a la ingobernabilidad. Los gobiernos multipartidistas por el contrario amplían el pluralismo político del sistema trasladando los principales valores de la democracia al escenario político. La adopción de acuerdos interpartidistas desde diversas perspectivas ideológicas a problemas colectivos a partir de la colaboración y el diálogo democrático y, la implementación de soluciones compartidas refuerza los lazos de pertenencia a la comunidad política y consolida la legitimidad del sistema político.

Desde este punto de vista, los factores que rodean y condicionan la formación de gobiernos de coalición se encuentran íntimamente vinculados con el fortalecimiento del sistema democrático. La toma de decisiones a través de la deliberación y del consenso, propicia una democracia consociativa, la más adecuada para resolver los conflictos en sociedades multiculturales y plurinacionales. Además, la necesidad de crear mayorías parlamentarias sitúa al Parlamento en el centro de la actividad política y otorga una importancia central al diálogo político, además de ofrecer un mayor protagonismo a los grupos políticos minoritarios. Junto a ello, la negociación para la formación de gobiernos de coalición pone de relieve la definición de objetivos partidistas que hagan compatible la expresión de los valores democráticos con la lógica voluntad de influir en el gobierno; de igual modo, trasladan a la ciudadanía el respeto por la diversidad, la tolerancia, el consenso, la integración y el gobierno compartido, entre otras muchas virtudes. Pero también es cierto que gobernar en coalición exige de habilidad política, de un mayor dominio del arte de la política y, sobre todo, de toma de decisiones por parte de los partidos que conforman la coalición lo que puede generar dificultades entre facciones en el seno interno de las organizaciones ${ }^{4}$. Estos gobiernos multipartidistas son, en ocasiones, efímeros y transitorios por ser soluciones racionales adoptadas en determinadas condiciones y bajo específicas circunstancias políticas.

4 Como señala Luebbert, los líderes de los partidos están motivados tanto por alcanzar cargos políticos como por el deseo de permanecer como líderes de su organización partidista. Ver en este sentido, M. LUEBBERT, G., «Coalition theory and government formation in multiparty democracies», Comparative Politics, $\mathrm{n}^{\circ} 15$, 1983 , pp. 235-249. 
La formación de gobiernos en sistemas multipartidistas ha sido objeto de relevantes estudios en el campo de la ciencia política. Las formulaciones teóricas sobre coaliciones de gobierno intentan explicar principalmente los procesos de formación de coaliciones políticas. Los diversos modelos y diseños de investigación abarcan desde los de carácter formal, generados a través de la teoría de la elección racional y la teoría de juegos que ofrecen análisis descriptivos y estudios comparados, hasta nuevos enfoques de carácter multidimensional que amplían la aproximación formal de las coaliciones, basados en enfoques empíricos e inductivos que infieren generalizaciones de análisis sistemáticos a partir de la aplicación de complejas simulaciones computacionales. No obstante, el marco de la investigación adolece aún de integración, tal es así que la mayoría de los modelos explicativos sobre la formación de gobiernos abordan los roles desempeñados por los partidos políticos, analizan el impacto y la influencia entorno institucional, o incluso, pronostican la distribución del reparto de carteras ministeriales, entre otros variados aspectos.

El empleo del término coaliciones gubernamentales remite a los elementos de la negociación expresados en reparto de carteras ministeriales o en posiciones ideológicas 5 . De esta forma ser miembro de un gobierno de coalición conlleva la titularidad de un ministerio y además el apoyo de la mayoría absoluta en el parlamento. En un sentido más amplio a veces se utiliza el término coaliciones políticas para hacer referencia a apoyos parlamentarios de partidos que no entran a formar parte del gobierno, pero esta acepción puede generar, en ocasiones, errores $^{6}$. Aunque bien es cierto que partidos que no forman parte del gobierno pueden otorgar a éste un apoyo parlamentario a largo plazo, dando lugar a lo que se conoce como «coaliciones de votación estables». Sin embargo, aún a pesar de que ese tipo de apoyo haya requerido de una negociación previa a la formación del gobierno, parece apropiado delimitar el concepto de gobierno de coalición al hecho de participar en el gobierno y, por tanto, basar este término en el principio de poder compartido ${ }^{7}$.

La publicación de la obra de William Riker «The theory of political coalitions» ${ }^{8}$ marca la senda por la que transcurren los estudios de carácter formal que aplican la racionalidad al ámbito de la política ${ }^{9}$. Los objetivos que persiguen los actores políti-

5 No consideramos a las coaliciones electorales por ser actores que se construyen en escenarios previos y por tanto poseen entidad propia tras las elecciones.

6 Esta ampliación del objeto de estudio se aplica para analizar el caso italiano, no obstante, no conlleva ninguna connotación de permanencia o de estatus institucional. Ver en este sentido, PridHAM, G. (ed.), Coalitional behavior in theory and practice. An inductive model for Western Europe, Cambridge, Cambridge University Press, 1986.

7 A. Robles señala este aspecto como imprescindible para identificar al gobierno de coalición, ver Robles, A., «Coaliciones políticas y sistema democrático», REP, nº 105, 1999, pp. 279-294.

8 Riker, W., The theory of political coalitions, New Haven, Yale University Press, 1962.

9 La teoría de juegos parte de la racionalidad plena del comportamiento humano de la cual se deduce un modelo exacto basado en las regularidades de dicho comportamiento en circunstancias concretas. Presupone que la composición del proceso decisional se asienta en una serie de decisiones elementales, consecutivas y ordenadas. Las propiedades que caracterizan a ese orden son la conectividad, por la que cada ordenación 
cos determinan aquello que intentarán maximizar con su comportamiento. Este estudio parte de la premisa de que los partidos políticos están motivados para alcanzar el poder y la recompensa es la obtención de carteras ministeriales. El modelo de coaliciones que analiza descansa en el tamaño de los partidos con representación en el parlamento. Riker diseña una teoría que alumbra el concepto de «coalición mínima vencedora» al identificar coaliciones que se caracterizan por tener la magnitud mínimamente necesaria para asegurar el apoyo parlamentario ${ }^{10}$. Así, la estrategia de la formación de la coalición de gobierno tiende a optimizar el número de escaños para garantizar la mayoría, sin incluir a ningún partido que no sea estrictamente necesario para alcanzarla. Esta propuesta no predice la formación de una coalición, sino que ofrece un amplio abanico de posibilidades. Entre ellas, las coaliciones predominantes que son las que se forman con partidos adyacentes en el espacio ideológico unidimensional. Esta estrategia facilita el reparto de carteras ministeriales, permite la adopción de acuerdos parlamentarios y la obtención de cualquier otro beneficio para los partidos integrantes de la coalición. Bajo este supuesto, la deserción de un partido que integre la coalición convierte en minoritario al gobierno y por tanto conduce a la inestabilidad gubernamental. Por ello, es indispensable en todo proceso negociador alcanzar los acuerdos entre los partidos en un clima de cooperación, lo que asegura en mayor medida la estabilidad y la permanencia de la coalición.

Gamson desarrolla esta línea de investigación y centra el análisis en el reparto de las carteras ministeriales que se alcanza tras la negociación entre los partidos ${ }^{11}$. Constata que los partidos políticos tratan de minimizar el tamaño de la coalición para maximizar su recompensa, en otras palabras, los partidos pretenden que el reparto de las carteras ministeriales se realice entre un menor número de actores políticos para así obtener mayores beneficios. Considera que esta asignación se realizará de forma proporcional al número de escaños con los que los partidos constituyen la coalición de gobierno. Esta robusta regularidad empírica de reparto de carteras a los partidos en proporción a los escaños obtenidos es lo que se denomina la regla de proporcionalidad o Ley de Gamson. El estudio de los gobiernos de coalición de 14 países de Europa occidental ilustra este fenómeno ${ }^{12}$. Los análisis ofrecen evidencia empírica de la proporcionalidad entre el número de carteras asignadas a los partidos y los escaños que dichos partidos ocupan en el parlamento (ver gráfico 1$)^{13}$. Sin

responde a la estructura del medio en la que surge; y la transitividad, que expresa una propiedad de las preferencias individuales. La teoría de juegos analiza el mecanismo de decisión partiendo de situaciones sencillas, en las que el individuo que juega busca su propio beneficio.

10 Hindmoor, A., y Brad, T., Rational Choice, Londres, Palgrave, 2015, p. 85.

11 Gamson, W. A., "A theory of coalition formation», American Sociological Review, n 26, 1961, pp. $373-382$.

12 Warwick, P. V. y Druckman, J. N., «The portfolio allocation paradox: an investigation into the nature of a very strong but puzzling relationship», European Journal of Political Research, $\mathrm{n}^{\circ}$ 45, 2006, pp. 635-665.

13 Este fenómeno también se aprecia en el reparto de carteras en los gobiernos autonómicos de coalición en España. Ver Falcó-Gimeno, A., «El reparto de poder en los gobiernos de coalición autonómicos. La 
embargo, esta uniformidad ha puesto de manifiesto una notoria contradicción cuando se toma en consideración la distribución de las carteras del gabinete. La medición del valor o la prominencia de cada una de estas carteras es un aspecto completamente diferente al número de carteras que obtienen los partidos. Si se parte de la premisa de que los beneficios en las transacciones de la formación de la coalición son las carteras y la influencia política que proporcionan, entonces, es evidente que se debe considerar no solo el número de carteras que recibe cada partido en el gabinete, sino también la importancia que denotan esas carteras ministeriales. De hecho, este aspecto es de singular importancia en las negociaciones que guían acuerdos de coalición. Además, en un estudio posterior, Browne and Franklin mostraron que, en coaliciones integradas por un menor número de partidos, los partidos pequeños por su poder de negociación o de chantaje político obtenían más beneficios en el sentido de ocupar ministerios relevantes a pesar de que la proporción de escaños era menor que los que alcanzaban otros partidos ${ }^{14}$.

\section{Gráfico 1. Proporción de escaños y proporción de carteras ministeriales en Europa (1945-2000)}

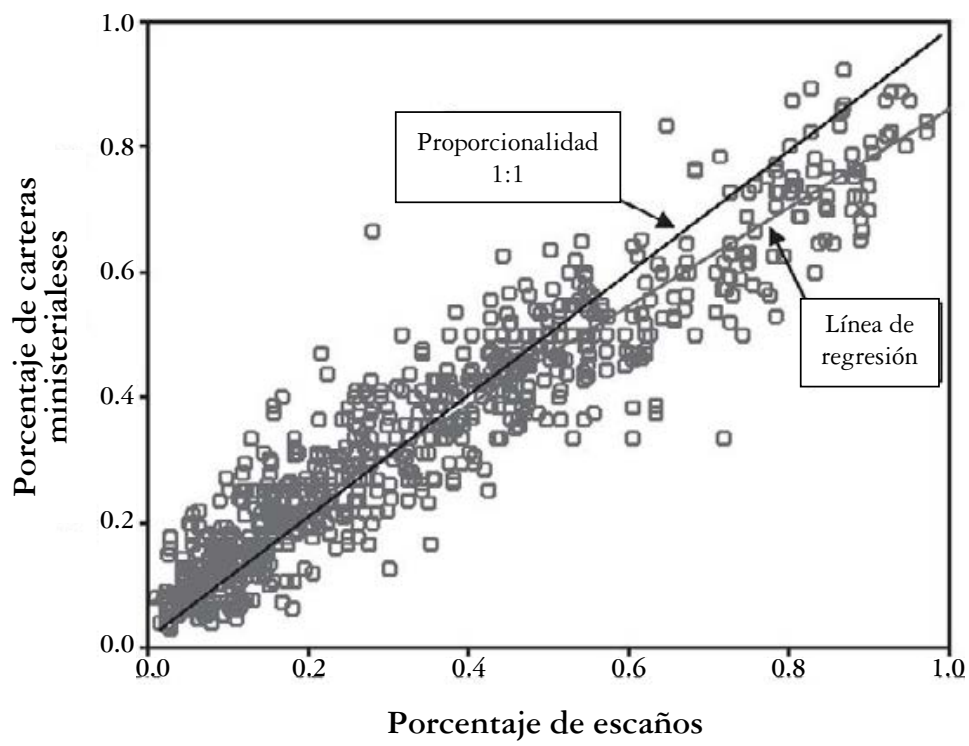

Fuente: Adaptado de Warwick y Druckman (2006).

ley de Gamson en España (1980-2010)», en RENIU, J. (ed.), Pactar para gobernar: dinámicas coalicionales en la España multinivel, Tirant lo Blanch, Valencia, 2013, pp. 179-204.

14 Browne, E. C., y Franklin, M.N., «Aspects of coalition payoffs in European parliamentary democracies», American Political Science Review, n 67, 1973, pp. 453-469. 
Los teóricos formales de las coaliciones políticas asumen que sólo puede ser ganadora aquella coalición que posea el control de la mayoría absoluta en el parlamento. El principal problema de estas teorías es su carácter estático al no prestar atención suficiente a los acontecimientos de índole política. Las teorías multidimensionales han ofrecido nuevas líneas para comprender los factores que guían la formación de los gobiernos de coalición poniendo de manifiesto el complejo entramado de elementos que influyen y condicionan el sistema de partidos sobre el que pivota el proceso de negociación de las coaliciones ${ }^{15}$. El fenómeno coalicional se aborda como un proceso continuo y dinámico en el que los programas políticos, las estrategias electorales y los ciclos vitales de los gobiernos de coalición centran buena parte del desarrollo teórico. De esta forma la ideología asume un papel predominante en las investigaciones al proporcionar líneas interpretativas de la formación de coaliciones que parten del supuesto de que la prioridad de los partidos políticos son las políticas públicas en vez de la obtención de cargos ministeriales. Esto significa que es irrelevante el número de partidos que integran la coalición de gobierno, y lo que desempeña un papel indiscutible en las negociaciones es la posición ideológica de los partidos en torno a las políticas públicas a desarrollar. Las coaliciones de gobierno se alcanzan entre aquellos partidos que están «conectados» o por lo menos cercanos unos a otros en el espacio ideológico. En este caso, los partidos centrales del espectro político parlamentario pueden ser -dada la mínima distancia política que les separa de los demás partidos-, el vínculo y medio de integración entre los partidos de la coalición, y así desempeñan un papel protagonista en la escena negociadora. Los modelos espaciales de voto ponen de manifiesto que es más probable que se formen coaliciones con una ganancia mínima e ideológicamente conectadas que otro tipo de acuerdos ${ }^{16}$. Y que el tamaño de un partido y la ubicación ideológica moderada aumenta la probabilidad de formar gobierno con varios partidos ${ }^{17}$. Además, se ha constatado que la tasa de supervivencia de gobiernos de coalición ideológicamente divididos es menor que la de aquellos que comparten aspectos ideológicos que facilitan la toma de acuerdos para implementar políticas ${ }^{18}$. Sin embargo, la mayoría de estas aproximaciones ignora el contexto institucional como un determinante del comportamiento de

15 De gran interés son los trabajos de Laver, M., y Schofield, N., Multiparty Governments: The Politics of Coalitions in Europe, University of Michigan Press, Ann Arbor, 1998; Müller, W. C. y STrøm, K., Coalition Governments in Western Europe, Oxford University Press, Oxford, 2000; y STRøм, K., Müller, W. C. y Bergman, T. (eds.), Cabinets and Coalition Bargaining: The Democratic Life Cycle in Western Europe, Oxford University Press, Oxford, 2008.

16 Martin, L. W. y Stevenson, R. T., «Government formation in parliamentary democracies», American Journal of Political Science, $\mathrm{n}^{\circ}$ 45(1), 2001, pp. 33-50.

17 B ̈̈ск, H. y Dumont, P., «Making the First Move», Public Choice, n ${ }^{\circ}$ 135(3-4), 2008, pp. 353-373.

18 WARWICK, P., «Coalition government membership in Western European parliamentary democracies», British Journal of Political Science, $\mathrm{n}^{\circ} 26,1996$, pp. 471-499. 
los partidos políticos. La estructura formal del sistema político plantea limitaciones, pero también en ocasiones estímulos para facilitar la negociación. Así, las relaciones gobierno-oposición, el sistema electoral, las reglas para la formación de gobiernos y sus efectos durante el proceso coalicional, así como la interacción de diversas arenas políticas, entre otros elementos, ponen de manifiesto la influencia que ejerce el marco institucional sobre las dinámicas de formación de gobierno multipartidistas.

Estudios más recientes sobre coaliciones dirigen su atención hacia el análisis de los motivos o justificaciones que conducen a los partidos a optar por la coalición y así determinar sus estrategias en el proceso negociador. Si bien las teorías formales habían incorporado algunos de estos elementos, como es la búsqueda del poder a través de las carteras ministeriales, este nuevo enfoque propone tipologías motivacionales del comportamiento de los partidos en base a las utilidades y los costes que se asocian al proceso de formación de coaliciones y, además, pone de relieve la importancia del entorno en el cual los actores toman las decisiones ${ }^{19}$. Íntimamente relacionado con esta aproximación se estudia el impacto que tienen acontecimientos procedentes del ambiente sobre la estabilidad de los gobiernos. Las investigaciones identifican las causas del desequilibrio y las potenciales explicaciones de la duración de las coaliciones analizando las dinámicas intrapartidistas ${ }^{20}$, identificando las causas de la ruptura de coaliciones gubernamentales ${ }^{21}$, o la (in)estabilidad ministerial ${ }^{22}$. Se constata que factores desestabilizantes como la incertidumbre y la complejidad de los acuerdos inciden en la duración de las negociaciones afectando directamente

19 Un referente en este campo de análisis es Torbjörn Bergman quien elabora un esquema en el que cada decisión tomada por un partido en el proceso negociador responde a la evaluación de los efectos que implica para la consecución de sus objetivos. En este sentido remitimos a su obra Bergman, T., Constitutional rules and party goals in coalition formation. An analysis of winning minority governments in Sweden, Umea Universitet, Umea, 1995.

20 Bassi, A., «A model of endogenous government formation», American Journal of Political Science, $\mathrm{n}^{\circ}$ 57(4), 2013, pp. 777-793; Diermeier, D. y Merlo, A., «An empirical investigation of coalitional bargaining procedures», Journal of Public Economics, n 88(3-4), 2004, pp. 783-797; Diermeier, D. y Vlaicu, R., «Parties, coalitions, and the internal organization of legislatures», American Political Science Review, $\mathrm{n}^{\circ} 105(2)$, 2011, pp. 359- 380.

21 Ansolabehere, S., Snyder, J. M., Strauss, A. B., y Ting, M. M., «Voting weights and formateur advantages in the formation of coalition governments», American Journal of Political Science, $\mathrm{n}^{\circ}$ 49(3), 2005, pp. 550-563; Giannetti, D. y Sened, I., «Party competition and coalition formation», Journal of Theoretical Politics, $\mathrm{n}^{\circ}$ 16(4), 2004, pp. 483-515; Martin, L. W. y Stevenson, R. T., «The conditional impact of incumbency on government formation», American Political Science Review, $\mathrm{n}^{\circ}$ 104(3), 2010, pp. 503-518; MARTIN, L. W. y VANBerG, G., «Coalition policymaking and legislative review», American Political Science Review, no 99(1), 2005, pp. 93-106; Volden, C. y CarrubBa, C. J., "The formation of oversized coalitions in parliamentary democracies», American Journal of Political Science, $\mathrm{n}^{\circ}$ 48(3), 2004, pp. 521-537.

22 Huber, J. D. y Martínez-Gallardo, C., «Replacing cabinet ministers: patterns of ministerial stability in parliamentary democracies», American Political Science Review, $\mathrm{n}^{\circ}$ 102(2), 2008, pp. 169-180; Laver, M. y Shepsle, K., Making and breaking governments, Cambridge University Press, Cambridge, 1996. 
sobre la adopción de los acuerdos de gobierno y resaltando el elemento dinámico de los estudios que se abordan bajo esta perspectiva ${ }^{23}$.

\section{LA GOBERNABILIDAD EN ESPAÑA}

Resulta sorprendente que, en la práctica política democrática de más de 40 años, hasta 2020 no se haya formado un gobierno multipartidista, máxime cuando España tiene una amplia experiencia en acuerdos de coalición en el ámbito autonómico y los gobiernos formados por más de un partido han sido en este nivel subnacional, más una norma que una excepción. Las elecciones celebradas en el período 1979-2019 han ofrecido resultados muy diversos, y entre ellos los partidos no siempre han logrado mayorías absolutas en el Congreso de los Diputados. Situando a España en el contexto europeo, nuestro país se convierte en este sentido, en una verdadera singularidad por el hecho de que todos los países de nuestro entorno, con mayor o menor frecuencia han investido gobiernos multipartidistas (ver tabla 1). En Europa del norte, con amplia tradición en este formato de gobiernos, todos los posibles gobiernos desde 1989 a 2010 han sido de ejecutivos de coalición (así ha ocurrido en Bélgica, Dinamarca, Finlandia, Islandia, Luxemburgo y Países Bajos). También en el centro de Europa han dominado este tipo de gobiernos (en Alemania y en Austria, por ejemplo), ampliándose esta relación si dirigimos la mirada hacia el sur y el este europeo (el caso de Italia o de Eslovenia). En otros países la frecuencia de gobiernos de coalición ha sido también elevada, como en República Checa, Estonia o Letonia.

La mayor diferencia entre los países europeos se aprecia al considerar la duración de este tipo de gobiernos de coalición. Aunque en algunas ocasiones se han agotado las legislaturas, la variabilidad entre países es significativa. Letonia, Polonia o Rumanía han sufrido procesos de inestabilidad gubernamental más frecuentes, de ahí un índice de duración menor. Por el contrario, en los países nórdicos de Finlandia, Islandia, Noruega o en Luxemburgo la estabilidad de los gobiernos de coalición ha sido la nota dominante. La ya larga trayectoria en este tipo de gobiernos permea hasta su cultura política cimentando unas pautas de normalidad aceptadas tanto por las élites políticas como por la ciudadanía. Este es su carácter distintivo, una cultura coalicional que no implica ingobernabilidad o crispación de la vida política. Y quizás, se debería añadir como variable explicativa el diseño institucional de estos sistemas políticos. Los países escandinavos son estados unitarios y de tamaño pequeño, dotados con procedimientos de investidura negativa y mecanismos únicos de disolución parlamentaria, elementos sin duda con influencia sobre la formación de los gobiernos.

23 Huber J. D. y Mccarty, N., «Cabinet decision rules and political uncertainty in Parliamentary Bargaining», American Political Science Review, n 95(2), 2001, pp. 345-360; DE WINTER, L. y DumONT, P., «Uncertainty and Complexity in Cabinet Formation» en StrøM, K., Müller, W. C., y Bergman, T. (eds.), Cabinets and coalition bargaining: the democratic life cycle in Western Europe, Oxford University Press, Oxford, 2008, pp. 123-158. 
Tabla 1. Gobiernos de coalición en Europa (1989-2010)

\begin{tabular}{|c|c|c|c|c|c|c|}
\hline \multirow[b]{2}{*}{ Países } & \multirow{2}{*}{$\begin{array}{l}\text { Número de } \\
\text { Gobiernos }\end{array}$} & \multicolumn{3}{|c|}{ Gobiernos minoritarios } & \multicolumn{2}{|c|}{ Duración media } \\
\hline & & $\begin{array}{c}\text { Único } \\
\text { partido }\end{array}$ & Coalición & Total & Relativa & $\begin{array}{c}\text { Absoluta } \\
\left(\mathrm{n}^{\circ} \text { de días }\right)\end{array}$ \\
\hline Alemania & 7 & 0 & 7 & 7 & 0.988 & 1386.5 \\
\hline Austria & 8 & 0 & 8 & 8 & 0.766 & 991 \\
\hline Bélgica & 10 & 0 & 10 & 10 & 0.559 & 303.5 \\
\hline Bulgaria & 8 & 2 & 1 & 3 & 0.494 & 611 \\
\hline Dinamarca & 9 & 0 & 9 & 9 & 0.692 & 825 \\
\hline Eslovaquia & 10 & 1 & 9 & 10 & 0.668 & 439 \\
\hline Eslovenia & 12 & 0 & 12 & 12 & 0.802 & 580.5 \\
\hline España & 6 & 4 & 0 & 4 & 0.962 & 1362 \\
\hline Estonia & 12 & 2 & 10 & 12 & 0.522 & 665 \\
\hline Finlandia & 10 & 0 & 10 & 10 & 1 & 720.5 \\
\hline Francia & 11 & 2 & 4 & 6 & 0.770 & 539.5 \\
\hline Grecia & 10 & 1 & 2 & 3 & 0.539 & 785.5 \\
\hline Holanda & 9 & 0 & 9 & 9 & 0.823 & 1113 \\
\hline Hungría & 10 & 2 & 6 & 8 & 1 & 691 \\
\hline Irlanda & 8 & 0 & 8 & 8 & 0.598 & 924 \\
\hline Islandia & 10 & 0 & 10 & 10 & 1 & 613 \\
\hline Italia & 13 & 0 & 13 & 13 & 0.452 & 358 \\
\hline Letonia & 19 & 1 & 18 & 19 & 0.315 & 307.5 \\
\hline Lituania & 12 & 0 & 6 & 6 & 0.627 & 340 \\
\hline Luxemburgo & 6 & 0 & 6 & 6 & 1 & 1772 \\
\hline Noruega & 9 & 4 & 5 & 5 & 1 & 959.5 \\
\hline Polonia & 16 & 5 & 11 & 16 & 0.343 & 410.5 \\
\hline Portugal & 7 & 3 & 2 & 5 & 0.994 & 874 \\
\hline Reino Unido & 7 & 0 & 1 & 1 & 0.833 & 1236 \\
\hline Rep. Checa & 10 & 2 & 8 & 10 & 0.579 & 459 \\
\hline Rumania & 17 & 4 & 11 & 15 & 0.467 & 440.5 \\
\hline Suecia & 7 & 4 & 3 & 7 & 1 & 1262.5 \\
\hline TOTAL & 273 & 38 & 199 & 233 & 0.728 & 610 \\
\hline
\end{tabular}

Fuente: Adaptado de Bergman et al, 2015. 
España es, como ya se ha señalado, el único caso que se desvía de estas dinámicas coalicionales apreciadas en el continente europeo. En nuestro país hasta 2020 no se ha formado ningún gobierno de coalición a nivel estatal ${ }^{24}$. Esta falta de experiencia política sólo es propia de este nivel de gobierno pues se han configurado gobiernos de coalición surgidos de procesos electorales autonómicos en Andalucía, Aragón, Canarias, la Comunidad Foral Navarra o el País Vasco, en diversas legislaturas. Bien es cierto que la transformación de los sistemas de partidos tras las elecciones autonómicas de mayo de 2019 ha incrementado el número de gobiernos de coalición, y solo en un número reducido de Comunidades gobierna un partido en solitario. Esta profusión en el uso de diversas soluciones coalicionales en el ámbito autonómico se ha trasladado al ámbito estatal finalizando con la singularidad que caracterizaba a nuestro sistema político.

En España, hasta la fecha se han formado quince gobiernos de ámbito estatal, resultantes todos ellos de convocatorias electorales con la excepción de dos: el gobierno presidido por Leopoldo Calvo-Sotelo en 1981, y el gobierno de Pedro Sánchez surgido a raíz de la primera moción de censura constructiva que prospera en el parlamento español en 2016. De entre todos los gobiernos, nueve han sido gobiernos minoritarios frente a cinco gobiernos mayoritarios, por tanto, si se hace un balance, han sido más los gobiernos minoritarios que se han constituido a lo largo de la etapa democrática. Estos datos sitúan a España en el grupo de países europeos con la frecuencia más elevada de gobiernos minoritarios.

Los gobiernos que no obtienen el apoyo mayoritario de un solo partido para gobernar son el reflejo de las transformaciones acontecidas en nuestro sistema de partidos. Los dos primeros gobiernos minoritarios se sitúan en el período de la Transición y en el inicio de la etapa democrática: Suarez I (19771979) y Suárez II (1979-1981), estando estrechamente relacionados con una etapa fundacional del nuevo régimen político, en el que los partidos políticos que competían por el electorado estaban a su vez procediendo a una configuración institucional. Ha de pasar un período amplio de tiempo hasta que a mediados de los años noventa se reproduce de nuevo este patrón de gobiernos minoritarios, pero esta vez con unas características muy diferentes: en 1993 González no revalida la mayoría absoluta de la que había disfrutado en las tres legislaturas anteriores, y seguidamente, en 1996 el primer gobierno de Aznar también necesitó el apoyo parlamentario de PANE para lograr ser investido por la cámara baja. Estos dos gobiernos representan un cambio de gran envergadura en las orientaciones electorales, pero no en el sistema de partidos, asegurando

24 No obstante, sí se aprecian pautas colaborativas y de apoyo entre los grupos parlamentarios de signo ideológico diferente en el seno de las comisiones parlamentarias lo cual es una paradoja del comportamiento político a nivel estatal que no haya dado lugar a una negociación que fructifique en un acuerdo coalicional. 
ambos una elevada estabilidad gubernamental. Más recientemente la profunda transformación del sistema de partidos ha conducido a lo que podría ser «una cronificación» de la ingobernabilidad del sistema ${ }^{25}$. El gobierno de Rajoy II (2016-2018) inaugura una etapa de mayoría insuficiente en el Parlamento para desempeñar la acción gubernamental, fenómeno extensible al posterior gobierno de Sánchez I (2018-2019) y al gobierno de coalición de Sánchez-Iglesias. Siguiendo esta misma estela, los resultados de las primeras elecciones generales celebradas en 2019 condicionaron la formación de gobierno cuyo fracaso condujo a una nueva convocatoria electoral a finales de ese mismo año, con notable incertidumbre respecto de sus resultados y a cerca del potencial de gobernabilidad que de ellas se derivara.

El análisis del proceso de toma de decisiones en estos contextos revela cómo los principales actores involucrados en la formación de gobierno en España han optado repetidamente por no formalizar gobiernos de coalición, con la excepción del último gobierno formado, fundamentalmente por una serie de intereses particulares. En todos los casos las ofertas negociadoras han sido dirigidas por los partidos de ámbito estatal (UCD, PSOE y PP) hacia PANE. Ello se debe, en primer lugar, a las diferencias evidentes de ambos tipos de partidos en lo que a sus objetivos intrínsecos se refiere: los primeros especialmente interesados en liderar el gobierno, obtener cargos ministeriales y aprobar sus políticas; mientras que los segundos, centraban sus objetivos principalmente en el mantenimiento y potenciación de su estatus político en su ámbito territorial. Pero no sólo este ha sido el factor coadyuvante de este tipo de gobiernos, a ello debe unirse, la facilidad que brinda nuestro sistema político en el ejercicio de la investidura de un nuevo gobierno. No se necesita disponer de la mayoría absoluta de los escaños en el Congreso de los Diputados, sino que el umbral de apoyo se rebaja hasta lograr un mayor número de votos a favor que de votos en contra. Así, en un primer momento no es requisito necesario la mayoría absoluta como punto efectivo de decisión para la formación de gobierno, si bien con posterioridad sea un factor determinante para la aprobación de las principales leyes en el Parlamento. Esta lógica instrumental ha auspiciado la formación de gobiernos minoritarios unipartidistas en España hasta 2015, si bien el cambio del formato del sistema de partidos adquiere otras connotaciones con efectos directos sobre la formación de los gobiernos del período 2016-2019 y resultando en el primer gobierno de coalición surgido de la investidura celebrada en 2020.

25 En cierto sentido este fenómeno se aprecia también en otros contextos. Israel como consecuencia de la alta proporcionalidad de su sistema electoral va a celebrar una tercera convocatoria electoral en apenas doce meses consecuencia de la falta de acuerdos entre los partidos políticos para permitir la investidura del Primer Ministro. 


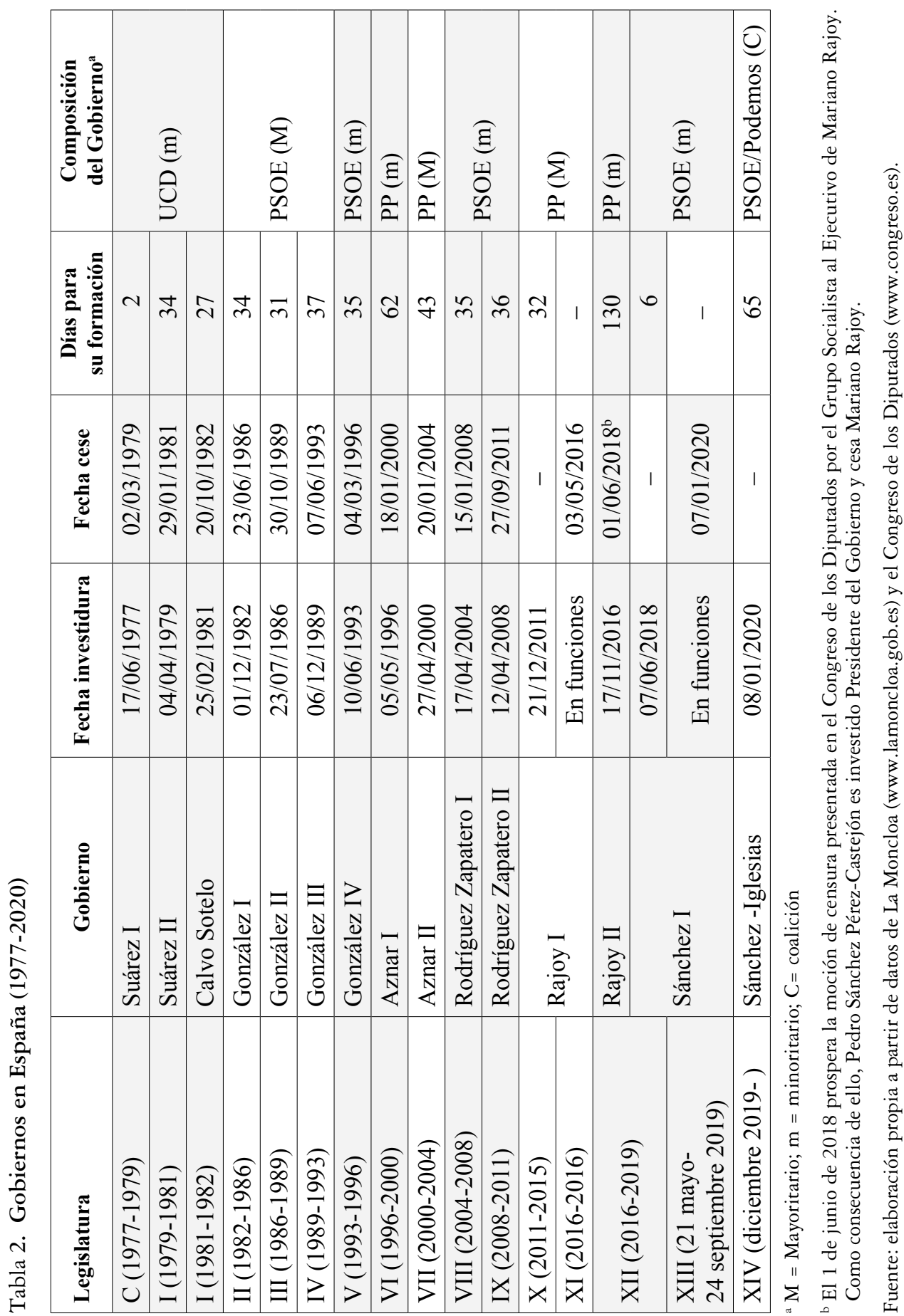


Los procesos negociadores de los gobiernos de coalición y la duración de las legislaturas responden a la voluntad de los partidos políticos asentados en los acuerdos alcanzados. En estos entornos, los partidos asumen ciertos riesgos asociados a costes o beneficios de diversa magnitud y carácter. Los cálculos estratégicos desarrollados por los actores políticos en nuestro país involucrados en los diferentes procesos decisionales han coincidido en valorar negativamente la corresponsabilización en la titularidad política del gobierno para, posteriormente, aceptar la formalización de un pacto de legislatura que garantice, en la medida de lo posible, la obtención de sus respectivos objetivos políticos. Tanto en el caso del gobierno de González IV (1993-1996) como en el gobierno Aznar I (1996-2000) se rechaza la propuesta de un gobierno de coalición para mostrarse dispuestos tanto el PSOE como el PP, respectivamente, a la formalización de un pacto de legislatura con fuerzas parlamentarias. Los motivos que justificarían esta decisión se localizan en el escenario electoral. Una valoración negativa del partido gubernamental podría favorecer un voto de castigo tanto en las elecciones generales siguientes como en las elecciones subnacionales que se celebrasen durante la legislatura. Conduciría a una pérdida de influencia política con un riesgo elevado. Parecida podría ser la evaluación de las utilidades esperadas, este caso de CiU, socio principal de los gobiernos minoritarios. La formación de un gobierno de coalición incidiría de forma negativa sobre sus objetivos autonómicos, principalmente sobre sus expectativas electorales frente al PSC-PSOE tanto en elecciones generales como en elecciones autonómicas. Este argumento es coherente si se analiza la labor política desarrollada por CiU en el ámbito estatal, centrada especialmente en una negociación bilateral con el gobierno central no sólo para la obtención de mayores competencias autonómicas o, en su defecto, contrapartidas económicas sino también con el objetivo de controlar a la oposición socialista en el gobierno de la Generalitat.

Este comportamiento estratégico también dominó las negociaciones de formación de gobierno en 1996, si bien con algunos matices diferentes. Aunque en esta ocasión el partido encargado de formar gobierno también dirigió sus ofertas iniciales hacia los partidos nacionalistas catalanes, vascos y canarios, de acuerdo con las diferentes posibilidades aritméticas que se le abrían tras los resultados electorales, la estrategia negociadora del PP se basó en el interés en liderar por vez primera el gobierno de la nación. Y desde la perspectiva del socio de gobierno, las elecciones autonómicas de 1995 habían dibujado un legislativo catalán en el que CiU precisaba de apoyos parlamentarios que le garantizasen la viabilidad política del sexto gobierno presidido por Jordi Pujol. La mejor opción para ambos socios fue la formalización de un pacto de legislatura que permitió el intercambien apoyos parlamentarios en sendos escenarios políticos. A diferencia del gobierno minoritario de González, Aznar alcanzó evidentes beneficios. Por un lado, el mayor aprovechamiento del tiempo de legislatura de todos los gobiernos españoles hasta la fecha y, por el otro, un rendimiento electoral que facilitó a los populares alcanzar la mayoría 
absoluta en las elecciones generales del año 2000. De hecho, el ejemplo ofrecido por la política española, en lo referido al nacimiento, vida y finalización de este primer gobierno Aznar es uno de los más paradigmáticos en lo que se refiere a la interconexión entre negociaciones, distribución de utilidades partidistas y estabilidad gubernamental ${ }^{26}$. Los cauces normalizados de las negociaciones entre ambos partidos consiguieron resolver en parte los conflictos y sus discrepancias asegurando la permanencia del Gobierno y, por tanto, dotando de estabilidad a la legislatura. Esto refleja una clara diferencia respecto a los dos gobiernos minoritarios de Suárez, que no contaron con apoyos estables y cuya tasa de supervivencia, o aprovechamiento de la legislatura arrojó valores inferiores a los de los gobiernos minoritarios de carácter formal que agotan la legislatura. Se constata por tanto que la estabilidad del gobierno guarda una relación íntima con las causas y mecanismos que determinan su final, pero también, con el contexto de su formación, tal y como se demuestra en el caso español ${ }^{27}$.

La victoria de Rodríguez Zapatero en las elecciones de 2004 y en las de 2008 abre un nuevo período de gobiernos minoritarios que requieren de la negociación para obtener la investidura del presidente del gobierno. La composición del Congreso de los Diputados tras estas convocatorias, dominadas ambas por la alta competitividad entre los principales partidos y una elevada concentración parlamentaria, dejan como único margen de maniobra al principal partido el establecimiento de pactos una vez más, con los PANE, y nuevamente a cambio de ciertos favores de tipo territorial, conformando un modelo de gobernabilidad caracterizado por una inexorable dinámica incremental de demandas ${ }^{28}$. Se constata cómo los pequeños partidos periféricos amplían su indiscutible poder de negociación, no sólo en el momento de la formación del gobierno sino también en su posterior mantenimiento. Su gran influencia sobre el funcionamiento del sistema político español en el que predomina la interrelación de múltiples arenas con diversos actores y objetivos partidistas, consolida un complejo juego de negociaciones entre partidos políticos que persiguen la satisfacción de utilidades muy diversas ${ }^{29}$.

26 Robles, A., «Negociaciones, Payoffs y estabilidad de los gobiernos de coalición», Revista de Estudios Políticos, no 126, 2004, pp. 91-112.

27 Un alto grado de estabilidad se mide a través de la duración de las legislaturas. Ésta es alta cuando alcanzan o sobrepasan los 800 días de vida media, como ha ocurrido en Austria, Irlanda, Luxemburgo y Holanda. En Suecia, Noruega, Alemania, Dinamarca, Francia, Portugal y Bélgica, la duración de los gobiernos se sitúa entre 500 y 800 días, caracterizándose como legislaturas de estabilidad media. Por último, países como Finlandia e Italia con una baja estabilidad por no superar sus gobiernos la media de 500 días de pervivencia. Ver Müller, W. y STrom, K., op. cit. pp. 585.

28 Porras, A., «Función de gobierno en la Constitución española, cuarenta años después», Revista de Derecho Político, $\mathrm{n}^{\circ}$ 101, 2018, pp. 99-122.

29 Reniu, J., «¿Merece la pena coaligarse? La formación de gobiernos minoritarios en España, $1977-$ 1996», Revista Española de Ciencia Política, n 5, 2001, pp. 111-142. 


\section{LA ATOMIZACIÓN PARLAMENTARIA DEL PERÍODO 2015-2019}

Hasta las elecciones de 2015 nuestro sistema electoral ha reforzado la posición de los partidos con mayor representación, dificultando la existencia de un partido bisagra de implantación nacional. Si bien el CDS e Izquierda Unida habrían reunido estas características, los retos organizativos de la primera fuerza y la implantación territorial de la segunda, penalizada por los efectos desproporcionales del sistema, no favorecieron su presencia en el Congreso de los Diputados ni les dotó de fuerza suficiente para convertirse en socios de gobierno. Frente a ellos, el sistema electoral ha facilitado la representación de las formaciones nacionalistas con amplio apoyo en su propio territorio e intereses particularistas. Este rasgo ha provisto, como acabamos de ver, las oportunidades para constituir gobiernos minoritarios en torno a una fuerza predominante susceptible de completar la mayoría parlamentaria a través de fórmulas distintas, en las que han desempeñado un papel protagonista los grupos parlamentarios nacionalistas. La identidad política de los PANE asentada en fracturas territoriales y no tanto en diferencias ideológicas permite que las contraprestaciones requeridas en las negociaciones se identifiquen con precisión en los intereses circunscritos a ese ámbito territorial al que representan. Este hecho facilita alcanzar acuerdos desde una perspectiva más pragmática, por revertir en el territorio las compensaciones obtenidas en los pactos de gobierno, y en especial en su propio electorado. Por tanto, es más factible lograr acuerdos de riesgo limitado para ambas partes, con un coste asumible para el partido que aspira a gobernar, y con beneficios visibles para los PANE, quienes se convierten en los árbitros del proceso negociador del gobierno estatal.

El diseño en la Transición de las instituciones políticas aseguraba la estabilidad y definió los límites de la gobernabilidad hasta que la transformación del sistema de partidos acontecida en 2015 altera el escenario. Un sistema electoral proporcional con un sesgo mayoritario, una moción de censura constructiva y otras prácticas parlamentarias, como el control al gobierno, han sido instrumentos favorecedores hasta recientemente de la gobernabilidad del sistema político. Aunque el sistema electoral aparentemente exitoso ha sido objeto de críticas sustantivas que justificarían las numerosas propuestas de modificación ${ }^{30}$ es cierto también que el sistema ha dado muestras de adaptación a circunstancias electorales variadas, ha facilitado la formación de gobiernos de distinto color político y ha sido testigo del nacimiento y desaparición de diversas fuerzas políticas. Sin modificar las normas electorales, los resultados de las convocatorias generales celebradas en 2015, 2016 y 2019 constatan un profundo cambio en el sistema de partidos resultante. El antaño sistema bipartidista que imperaba con altas dosis de moderación ideológica sufre una profunda transformación dando lugar a la

30 Montero, J. R. y Riera, P., «El sistema electoral español: cuestiones de desproporcionalidad y de reforma», Anuario de la Facultad de Derecho de la Universidad Autónoma de Madrid, n 13, 2009, pp. 225-270. 
configuración de un modelo multipartidista con consecuencias imprevistas sobre la estabilidad del sistema político.

El sistema electoral diseñado en la Transición y reproducido en la LOREG, tuvo la intención de favorecer la concentración de la representación política para evitar la excesiva fragmentación del parlamento y propiciar la estabilidad gubernamental, objetivo de vital importancia en el período fundacional de la democracia ${ }^{31}$. También se diseñó con un fuerte sesgo mayoritario, claramente orientado a facilitar apoyos a la opción política liderada en aquel momento por el Gobierno de Suárez ${ }^{32}$. Los objetivos propuestos han durado durante más de 30 años, a la vista de los resultados de las elecciones generales celebradas a lo largo de esta etapa. Este efecto reductor ha sido, por otra parte, la tónica durante todos los procesos electorales asemejando los resultados a la dinámica de los sistemas mayoritarios de Reino Unido y Francia. Se percibe a través de la reducción del número efectivo de partidos electorales cuyas cifras son progresivamente menores al número de partidos con representación en el Congreso (ver tabla 3). Durante un amplio período de tiempo dos grandes partidos de ámbito nacional han dominado la competición y a lo largo de varias legislaturas han concentrado más del 80 por ciento de los escaños asemejando el sistema de partidos políticos a un modelo «bipartidista». No obstante, han compartido hemiciclo con pequeños partidos nacionalistas o regionalistas, de ahí el calificativo de sistema bipartidista «imperfecto». Con la salvedad de los resultados de las elecciones de 1993 en los que estas fuerzas de menor tamaño se convierten en actores estratégicos en la negociación parlamentaria de un gobierno minoritario, no es hasta 2015 cuando los PANE y los nuevos partidos emergentes adquieren un papel indiscutible en la dinámica parlamentaria, como consecuencia de la desconcentración parlamentaria del sistema.

La entrada en la competición política de Ciudadanos y Podemos (y sus confluencias) quienes presentan candidatos todas las circunscripciones españolas, se constituye como el principal rasgo diferenciador de las elecciones generales celebradas en el período 2015-2019. El sistema electoral ha sido permisivo, en el sentido de ofrecer la posibilidad de obtener representación a un mayor número de partidos que competían en las circunscripciones españolas, y ello a pesar de su ya comentado sesgo mayoritario. Aunque la Constitución de 1978 establece que el reparto de escaños se haga de manera proporcional a los votos, los efectos del sistema electoral generan resultados

31 Las disposiciones electorales de la Ley para la Reforma Política que amparó la celebración de las elecciones de 15 de junio de 1977 se plasmaron en la Constitución de 1978 y serían reproducidas con posterioridad en la LOREG. Los efectos que se buscaban eran reforzar la opción bipartidista en el Congreso y Senado que había salido de las urnas en 1977, para imposibilitar un cambio en el sistema de partidos; y, privilegiar a la provincia sobre la comunidad autónoma.

32 O. Alzaga reconoció que el encargo que recibieron consistía en diseñar un conjunto de mecanismos que permitiera a Unión de Centro Democrático (UCD) alcanzar la mayoría absoluta de escaños en el Congreso con sólo el 36-37 por 100 de los votos. Ver Alzaga, Ó., «I rapporti tra Capo dello Stato, Governo e Parlamento», en Rolla, G. (ed.), Il X anniversario della Constituzione spagnola: bilancio, problemi, prospettive, Siena, Centro Stampa della Facoltà di Scienze Economiche i Bancarie, 1989, p. 127. 
que se alejan del ideal de la proporcionalidad. Ciertamente el uso de la fórmula D'Hont tiene un sesgo favorable a las fuerzas más votadas, y ello no es debido exclusivamente a la fórmula de transformación de votos en escaños ya que esa desviación se mitiga cuanto mayor es el tamaño de la circunscripción. Por tanto, es la magnitud de las circunscripciones el elemento del sistema electoral que ofrece más claves para comprender este alejamiento de la proporcionalidad. Así, cuanto menor sea la magnitud del distrito, más desproporcionales serán los resultados, ya que los escaños se repartirán entre un menor número de partidos quedando los votos de los partidos menores sin representación. Y, de forma contraria, cuanto más grande sea la magnitud de la circunscripción, mayor será la proporcionalidad al permitir la entrada de un número más elevado de partidos en la distribución de los escaños. En España se elige un promedio de siete diputados por provincia. Sin embargo, la variación del número de escaños asignados a cada una de las circunscripciones es importante, al predominar las circunscripciones pequeñas. Por ejemplo, de acuerdo con la distribución de escaños establecido para las elecciones generales de 2016, 104 de los 350 escaños que configuran el Congreso de los Diputados se eligen en 28 provincias con una magnitud muy pequeña, hasta cinco diputados, que son las que generan la mayor desproporcionalidad sobre el sistema de partidos; 129 escaños se eligen en 18 circunscripciones medianas que tienen asignados entre 6 y 10 diputados; y los restantes 117 escaños se eligen en 6 provincias con más de 10 diputados, que son las circunscripciones más proporcionales. Esta distribución muestra el predominio de circunscripciones en las que existiría un sesgo favorable a las fuerzas políticas más votadas. A pesar de ello, las elecciones de 2015 abrieron un espacio para la competición de más partidos en todas las circunscripciones. En particular, el pacto preelectoral de Podemos amplió su captación de votantes gracias a los resultados logrados en aquellas circunscripciones en las que existía una confluencia negociada con otras fuerzas políticas -En Marea en Galicia, En Comú en Cataluña y Compromís en Valencia. Uno de cada cuatro votantes en Pontevedra, Valencia y Barcelona apoyaron a las coaliciones auspiciadas por Podemos. De forma similar el éxito electoral de Ciudadanos se localiza en los grandes municipios de Madrid y Barcelona en los que se constata un efecto más proporcional del sistema electoral. Por tanto, la misma norma electoral que ha imperado en todos los procesos electorales celebrados en democracia ha facilitado la representación de un mayor número de opciones partidistas. Y lo ha hecho como consecuencia de la menor concentración de votos entre los dos primeros partidos, de ahí que lo singular del escenario electoral de 2015 sea no tanto la presencia de un mayor número de partidos como la fragmentación de los bloques ideológicos resultante. Los nuevos partidos políticos compiten por los votos de la izquierda, en un caso, y de la derecha ideológica en otro, erosionando los anclajes de los dos partidos tradicionales ${ }^{33}$.

33 La captación del voto a los nuevos partidos se explica por factores de coyuntura política asentados en el grave deterioro de la percepción social sobre el aumento de la corrupción y sobre el mal funcionamiento de la democracia en España además del impacto de la crisis económica y sus consecuencias más directas. Ver 
Hoy podemos confirmar que la etapa política más convulsa e inestable en términos de gobernabilidad acontece tras las elecciones generales de 2015 y se prolonga durante cuatro años. La pérdida de la mayoría absoluta de la que disponía el primer gobierno de Rajoy en el Parlamento abre un escenario de complejas relaciones entre los actores parlamentarios. No cabía la posibilidad de reeditar un gobierno minoritario con apoyos de socios nacionalistas porque la distribución de los escaños no facilitaba este tipo de acuerdos. La elevada fragmentación del arco parlamentario con presencia de un mayor número de grupos parlamentarios inicia uno de los procesos políticos más complejos desde la aprobación de la Constitución. El número de partidos políticos que obtiene escaños es elevado. Si aplicamos el índice de número efectivo de partidos advertimos que, en relación con las elecciones precedentes de 2011, el índice electoral se incrementa en 2.34 puntos y en 2.94 el índice parlamentario. Esto significa que los partidos que compiten electoralmente y los que denotan relevancia en el Congreso de los Diputados son numéricamente más que en la legislatura que se cerraba. Las consecuencias de ello obligan a tomar en consideración diversas fórmulas para lograr la investidura del gobierno. Es sabido que el sentido de la investidura en nuestro sistema constitucional se asienta en la elección de un presidente a la vez que, en la configuración en ese mismo acto, de una mayoría parlamentaria de gobierno que facilite la implementación del programa que presenta en la investidura, y por tanto vinculado al proyecto político por el que ha sido elegido en las urnas. Bajo esta lógica, la primera anomalía que se advierte en 2015 reside en que ningún candidato tenía asegurado el éxito en este proceso de investidura parlamentaria. Las vías negociadoras que se abrieron en aquel momento fraguaron en un impasse con consecuencias políticas de gran alcance. Por vez primera los dos partidos con potencial de coalición iniciaron un proceso de acercamiento a otros partidos, a posibles socios parlamentarios, para pergeñar acuerdos. Por un lado, el Presidente del gobierno en funciones Rajoy, cuyo partido obtuvo la mayoría de los escaños en el Congreso de los Diputados contactó con los líderes parlamentarios del PSOE y Ciudadanos para tratar de asegurar una mayoría de gobierno; y, por otro, el líder del PSOE desarrolló negociaciones paralelas para alcanzar una mayoría alternativa, principalmente con las fuerzas políticas que por vez primera lograron escaños, Ciudadanos y Podemos. Las negociaciones no alcanzaron ningún acuerdo de gobierno y los escaños del partido de Rajoy no le permitían el apoyo suficiente para asegurar la gobernabilidad y salir investido Presidente, de ahí que no aceptara el encargo del rey para formar gobierno, segunda anomalía generada. Sin disponer tampoco de apoyos suficientes para ser investido, la estrategia del líder del PSOE fue presentar su programa de gobierno ante el Congreso, quien, lógicamente, en votación no le otorga su confianza procediéndose a la disolución de las

en este sentido el trabajo de Hernández, E. y Kriesi, H., «The electoral consequences of the financial and economic crisis in Europe», European Journal of Political Research, n 55, 2016, pp. 203-224. 
Cortes Generales. Este acontecimiento significó otra novedad en el funcionamiento de nuestro sistema parlamentario. Las negociaciones posteriores entre partidos no pudieron evitar, la puesta en práctica del mecanismo de la disolución parlamentaria previsto en el art. 99 de la Constitución Española para el caso de que, transcurridos dos meses desde la primera votación de investidura, ningún candidato hubiera logrado la confianza de la Cámara. Los ciudadanos habían conformado a través de su voto un Congreso atomizado y con un equilibrio desigual que condujo a la incapacidad para adoptar acuerdos y configurar una mayoría parlamentaria suficiente para investir a un presidente como jefe del Ejecutivo.

Esta situación de bloqueo institucional condujo a la convocatoria de nuevas elecciones generales sobre las que las encuestas pronosticaban similares resultados a los de las elecciones anteriores. Y así ocurrió. La disolución de las Cámaras en 2016 y la convocatoria de elecciones no fue solo una consecuencia de los números, es decir, del nuevo reparto de diputados en la Cámara. El nuevo formato del sistema de partidos llegó para quedarse, augurando el inicio de una nueva etapa en nuestro sistema político. Se sustituye un sistema de partidos que pivotaba sobre dos grandes fuerzas de ámbito estatal, más un número de fuerzas más pequeñas de ámbito no estatal, por otro sistema de partidos construido alrededor de dos partidos grandes, dos de tamaño medio y varios PANE con desigual presencia parlamentaria: un sistema multipartidista con altas dosis de polarización. A este notable cambio cuantitativo se añade el profundo cambio de las posiciones políticas de los partidos nacionalistas catalanes cuya apuesta secesionista anulaba entonces su capacidad para servir de apoyo parlamentario a uno de los dos grandes partidos nacionales, desapareciendo por tanto su carácter de partido bisagra, de socio preferente de los pactos. Esta traslación del patrón territorial a un patrón ideológico es el primer síntoma del cambio político que se oteaba en el horizonte.

Las estrategias negociadoras para formar gobierno resultaron inviables. El bloqueo nacía de la imposibilidad de configurar mayorías vertebradas en torno a los dos grandes partidos de ámbito estatal: por un lado, ni aun contando con el eventual apoyo de partidos afines ideológicamente tales como Ciudadanos, el PNV y Coalición Canaria, el PP estaba en condiciones de lograr la investidura de su candidato a la presidencia del Gobierno, quien, en el mejor de los casos podía sumar 175 diputados frente al veto de otros tantos; por otro lado, la situación no era tampoco más ventajosa para el PSOE, que solo podía liderar una mayoría alternativa asumiendo la dimensión territorial a través de los votos de los partidos nacionalistas catalanes y sus exigencias políticas, inaceptables para buena parte de los socialistas. Un equilibrio de debilidades que condujo a un auténtico bloqueo una vez que Pedro Sánchez descartó por completo la única salida, la abstención de todos o una parte de los diputados socialistas, lo que podía evitar la repetición, por segunda vez, de las elecciones generales. Para eludir la nueva convocatoria, el grupo socialista en el Congreso pasó del voto en contra (del «no es no») al candidato popular, a la abstención, y asumió por ello un alto coste, resultando finalmente investido Mariano Rajoy con 170 votos a favor (los del PP, Ciudadanos y Coalición Canaria), 
Tabla 3. Número efectivo de partidos y niveles de concentración en elecciones legislativas (1977-2019)

\begin{tabular}{|l|c|c|c|c|c|}
\hline Elecciones & $\begin{array}{c}\text { Electoral } \\
(\mathbf{N E P e})\end{array}$ & $\begin{array}{c}\text { Parlamentario } \\
(\text { NEPp })\end{array}$ & $\begin{array}{c}\text { NEPe- } \\
\text { NEPp }\end{array}$ & $\begin{array}{c}\text { Concentración } \\
\text { electoral }\end{array}$ & $\begin{array}{c}\text { Concentración } \\
\text { parlamentaria }\end{array}$ \\
\hline $\mathbf{1 9 7 9}$ & 4,16 & 2,77 & 1,39 & 65,2 & 82,6 \\
\hline $\mathbf{1 9 8 2}$ & 3,33 & 2,32 & 1,01 & 74,5 & 88,3 \\
\hline $\mathbf{1 9 8 6}$ & 3,57 & 2,63 & 0,94 & 70,0 & 82,6 \\
\hline $\mathbf{1 9 8 9}$ & 4,16 & 2,77 & 1,39 & 65,4 & 80,6 \\
\hline $\mathbf{1 9 9 3}$ & 3,53 & 2,70 & 0,83 & 73,6 & 85,7 \\
\hline $\mathbf{1 9 9 6}$ & 3,28 & 2,72 & 0,56 & 76,4 & 84,9 \\
\hline $\mathbf{2 0 0 0}$ & 3,18 & 2,52 & 0,66 & 78,7 & 88,0 \\
\hline $\mathbf{2 0 0 4}$ & 3,10 & 2,50 & 0,60 & 80,3 & 89,1 \\
\hline $\mathbf{2 0 0 8}$ & 2,82 & 2,35 & 0,47 & 82,7 & 92,0 \\
\hline $\mathbf{2 0 1 1}$ & 3,41 & 2,60 & 0,81 & 73,3 & 84,6 \\
\hline $\mathbf{2 0 1 5}$ & 5,75 & 5,54 & 0,21 & 50,7 & 60,8 \\
\hline $\mathbf{2 0 1 6}$ & 5,32 & 4,09 & 1,23 & 55,6 & 63,4 \\
\hline Abril 2019 & 6,21 & 4,95 & 1,26 & 45,3 & 54,0 \\
\hline Noviembre 2019 & 6,20 & 4,73 & 1,47 & 48,8 & 59,4 \\
\hline
\end{tabular}

${ }^{a}$ El Índice del Número Efectivo de Partidos (NEP) de Laakso y Taagepera se calcula aplicando la siguiente fórmula: $\mathrm{NEP}=\frac{1}{\sum_{i=1}^{n} p i^{2}}$

Donde $\mathrm{p}_{\mathrm{i}}$ es la proporción de votos o de escaños obtenido por cada partido político.

b El Índice de Concentración electoral y parlamentaria hace referencia al porcentaje de votos o de escaños que suman los dos primeros partidos.

Fuente: Elaboración propia. Datos publicados por el Ministerio del Interior y la Junta Electoral Central.

68 abstenciones de los diputados socialistas ${ }^{34}$ y 111 votos en contra, entre los que debían contabilizarse quince de diputados del PSOE que no asumieron finalmente la posición de su grupo parlamentario. Esta es otra anomalía del sistema. Habían transcurrido 315 días desde que el Gobierno entrara en funciones y 130 días para para que se constituyera la nueva Cámara, elegida el 26 de junio de 2016, y se alcanzara la mayoría suficiente para otorgar la confianza, en segunda votación (por mayoría simple) al candidato a la presidencia, procediéndose así a la formación del II Gobierno de Rajoy. Un gobierno minoritario cuyo partido sólo disponía de 123 diputados (el 35 por ciento de los escaños de la cámara baja) y, por tanto, obligado a pactar con otras fuerzas parlamentarias para tener una mínima capacidad de gobierno. La legislatura fue compleja por la necesidad de diseñar estrategias negociadoras en el seno del legislativo.

34 Pedro Sánchez entregó su acta de diputado con anterioridad al pleno de investidura para no romper la disciplina de voto de su grupo parlamentario que por acuerdo Comité Federal optó por la abstención. 
El nuevo mapa de partidos había cambiado la dinámica de la gobernabilidad, pero no fue la única novedad en este corto período de tiempo. Dos mociones de censura se presentaron contra el Presidente del gobierno Mariano Rajoy. Una en mayo de 2017 liderada por 35 diputados perteneciente al grupo parlamentario confederal de Unidos Podemos-En Comú Podem-En Marea que situaba como candidato a la Presidencia al diputado Pablo Iglesias y que no prosperó en su votación en el Congreso de los Diputados al estar respaldada únicamente por 82 votos a favor, frente a 170 votos en contra (que procedían del PP, Ciudadanos y Coalición Canaria) y 97 abstenciones (apoyadas por los grupos parlamentario socialista, vasco y catalán). Y, una segunda moción de censura presentada por el grupo parlamentario socialista en junio de 2018, que contó con el apoyo del grupo parlamentario de Podemos, aprobada por el Pleno del Congreso y que sentó un precedente en la historia democrática española al prosperar y convertirse en un procedimiento «extraordinario de selección». Por vez primera, un candidato, Pedro Sánchez, sin ser diputado, fue el vencedor de una moción de censura tras reunir los apoyos de los diputados de su grupo parlamentario, de Unidos Podemos, y de los diversos PANE (ERC, PNV, PDeCAT, Compromís, Bildu y Nueva Canarias). El candidato se convierte, sin haber ganado unas elecciones y con un exiguo apoyo de un grupo parlamentario de 85 diputados, en el séptimo Presidente de Gobierno. Esta debilidad parlamentaria condicionó sobremanera la gobernabilidad de legislatura conduciendo al adelanto de las elecciones en 2019 tras el rechazo a la ley de presupuestos generales del Estado en el Congreso, y apenas transcurridos ochos meses desde el nombramiento del jefe del ejecutivo.

Según los pronósticos, los resultados de las elecciones de 28 de abril de 2019 constatan que tanto la competición electoral como los resultados del proceso consolidan la permanencia de preferencias electorales que conforman, en el nivel parlamentario, un sistema de partidos de corte multipartidista en el que además, el partido dominante no ocupa una posición central lo cual reduce las posibilidades de formar gobierno en solitario, por lo que debe contar con el apoyo de otros grupos parlamentarios para lograr la investidura y asegurar la estabilidad gubernamental. Este marco de incertidumbre gubernamental como ya conocemos no será el último. A pesar de la experiencia de gobiernos minoritarios, la debilidad del partido vencedor en las urnas y la presencia de un mayor número de fuerzas parlamentarias en el hemiciclo conduce a la formación de un gobierno de coalición que no asegura estabilidad a lo largo de la legislatura, fundamentalmente porque los socios de gobierno habían cambiado. Atrás quedan las etapas en las que los partidos nacionalistas apoyaban al gobierno a cambio de una serie de beneficios compatibles con las dinámicas del sistema. La (des)aparición y/o transformación de los partidos catalanes, así como la mayor presencia de estos actores en el hemiciclo de la carrera de los Jerónimos alteran las dinámicas gubernamentales. CiU había sido el «socio prioritario» de los gobiernos minoritarios, por disponer entre 10 y 17 escaños. Pero las dinámicas de la política autonómica en Cataluña, especialmente la territorial, han conducido a una transformación de gran calado. Sin entrar a analizar el proceso, y considerando sólo los efectos sobre la política estatal, el crecimiento de escaños de Esquerra Republicana de 
Cataluña y la desaparición de CiU, la fundación de la Democracia y Libertad, posteriormente Convergencia Democrática de Cataluña, y finalmente Junts por Cataluña, con una presencia mucho más reducida en escaños que la otrora citada CiU ceden el testigo de socio gubernamental a ERC. Aunque inicialmente el partido republicano no parecía ser una alternativa viable por su deriva independentista y su participación en el proceso de ruptura con la legalidad constitucional, su abstención ha sido determinante para facilitar la investidura del candidato Sánchez en 2020. Las posibilidades para conformar la mayoría absoluta en el Congreso alteran, por tanto, la dinámica negociadora de gobiernos minoritarios anteriores al ser indispensable ampliar la base de apoyos y, al sustentarse éstos en acuerdos programáticos y, por tanto, de afinidad ideológica. Pero es conveniente recordar que la composición del Congreso de los Diputados derivada de las elecciones generales de abril de 2019 a la resultante de las elecciones de noviembre de ese mismo año dista de ser semejante.

Los resultados electorales de abril de 2019 depararon una victoria del PSOE que incrementa en 39 los escaños en el Congreso, pero aún es insuficiente para alcanzar la investidura si no se logran pactos con otras fuerzas políticas. La fragmentación del Parlamento confirió a los partidos políticos un poder de negociación sustanciado en diversas combinaciones para alcanzar la mayoría, llegando a ser determinante de la duración de la negociación y del número de rondas necesario para alcanzar un presumible éxito en la formación del gobierno. Otra novedad. Al no haber un partido predomínante, solo cabían acuerdos entre el PSOE como socio principal y Unidas Podemos, o entre el PSOE y Ciudadanos, además, de los apoyos mínimamente necesarios de PANE que asegurasen la investidura. Así pues, las negociaciones se convierten de nuevo en la pieza clave para la formación del gobierno y de su mantenimiento posterior, sin que por el momento se plantease la fórmula de gobierno de coalición.

No cabe duda de que la formación de un gobierno de coalición genera intrínsecamente un conflicto entre los intereses de los partidos con diferente fuerza parlamentaria. Lo que resulta relevante para la constitución de coaliciones no son las coincidencias o discrepancias en las definiciones ideológicas genéricas, sino aquellas afinidades o divergencias que se producen respecto de proyectos y políticas concretas. Desde esta perspectiva, tras los resultados electorales de abril de 2019 la proximidad real del PSOE con relación a posibles socios era más compleja. Respecto de Ciudadanos por la antagónica posición sobre el tema de Cataluña; y, respecto de Podemos, aunque se perciben posiciones diferentes sobre cuestiones de política económica, sobre medidas para afrontar la crisis del empleo juvenil o respecto de la posición al proyecto europeo, lo que fue determinante fue el manifiesto interés de Podemos por formar parte del Gobierno, cuestión que no fue considerada inicialmente por Pedro Sánchez, pero ofrecida durante el proceso negociador ${ }^{35}$ y finalmente rechazada en los términos que impuso Podemos.

35 Durante las negociaciones celebradas en el mes de julio el Presidente en funciones Pedro Sánchez ofreció a Podemos la entrada en el Gobierno con una vicepresidencia social y tres ministerios. 


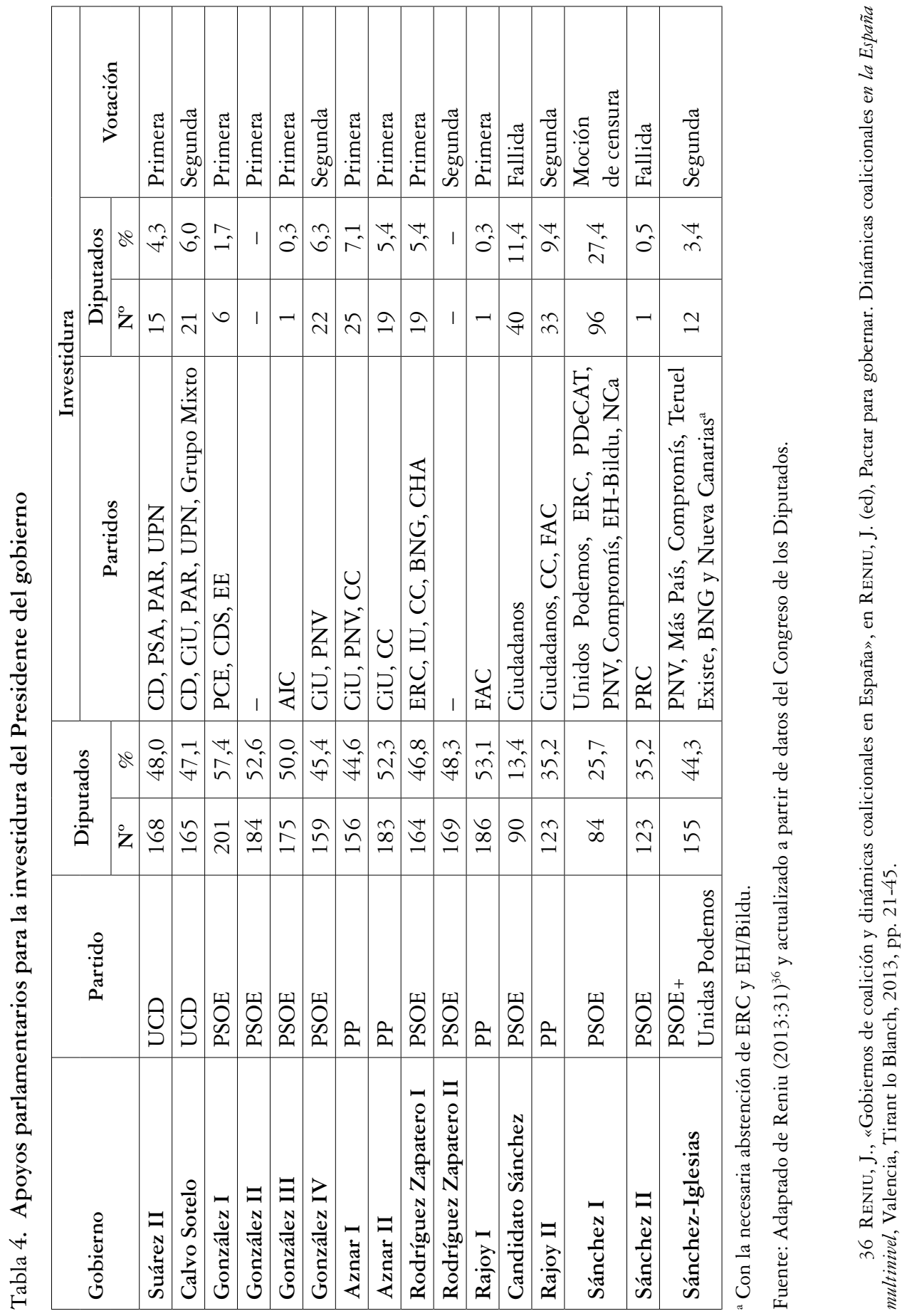


Como ya se ha señalado, los estudios sobre las negociaciones en procesos de coalición demuestran que, en la mayoría de los casos, la cantidad y calidad del premio obtenido por los partidos que negocian está condicionado por el número de partidos necesario para la formación del gobierno. A mayor número de partidos, menor recompensa en términos de carteras ministeriales o, incluso, respecto de la posibilidad de programar políticas de gobierno ${ }^{37}$. Pero si los partidos que integran la coalición están próximos en el espectro ideológico los beneficios pueden aún maximizarse. De lo anterior se deduce que tanto el PSOE como Podemos cumplían estas premisas, lo cual facilitaba, teóricamente, alcanzar un acuerdo. Sin embargo, también es cierto que conformar una coalición gubernamental requiere de la existencia de una sintonía previa entre los partidos y, por extensión, entre los líderes políticos ${ }^{38}$, además de una manifiesta habilidad de los actores implicados en las negociaciones para lograr alcanzar con éxito un acuerdo. La literatura sobre coaliciones ha confirmado la tesis de que la recompensa obtenida por los partidos en la negociación guarda una relación de proporcionalidad con su posición estratégica en el escenario político medido a través de su fuerza parlamentaria ${ }^{39}$. Y desde esta última perspectiva, Podemos se convierte en el partido con mayor poder de negociación, dado que era necesario en todas las posibles combinaciones numéricas para que el PSOE obtuviera la mayoría en el Congreso. Quizás este fue el factor con condujo al cambio de posiciones de Sánchez y valorar como opción un gobierno de coalición y al establecimiento de un proceso de negociación bidireccional. El PSOE era el partido que había vencido en las urnas, y por tanto le correspondería tomar la iniciativa. Elaboró un documento de medidas que coexistió con un documento propuesto por Podemos que contenía cuatro fórmulas para formalizar una coalición. Ambos partidos en el estadio negociador inicial delimitaron con firmeza sus posiciones negociadoras, sin un punto común de entendimiento, lo que imbuyó de incertidumbre a todo el proceso negociador. Ante esta situación el PSOE controló el desarrollo de las negociaciones marcando los tiempos. Durante el mes de julio se inician las reuniones que no abocan en acuerdo. El PSOE presenta la oferta programática, las garantías y la posibilidad de que el grupo de Pablo Iglesias entrara en las estructuras de poder, pero sin ministros, algo inaceptable para Podemos que insistía en un gobierno de coalición y un proceso negociador sin límites iniciales. Tal era la «fuerza» negociadora de Podemos que la oferta de Sánchez que rechaza es la de una vicepresidencia de Asuntos Sociales, que implicaba la presidencia de la comisión delegada para coordinar todas las políticas

37 Laver, M. y Budge, I., Party Policy and Governments Coalitions, Londres, MacMillan, 1992.

38 En este sentido cabe recordar que el Presidente del gobierno en funciones llegó a manifestar cuatro días antes de la sesión de investidura «que el principal escollo [para un gobierno de coalición] es Iglesias». El líder de Podemos respondió con un movimiento inesperado para muchos. Se apartó y decidió que el beneficio a alcanzar se incrementaría con su retirada.

39 Browne, E. y Franklin, M., «Aspects of payoffs in European parliamentary democracies», American Political Science Review, n ${ }^{\circ}$ 67(2), 1973, pp. 453-469. 
sociales del Gobierno, con los contenidos de las áreas de bienestar social y dependencia, incluido el Comisionado para la pobreza infantil, y tres ministerios, el de Vivienda y Economía Social; el de Sanidad, Asuntos Sociales y el ministerio de Consumo e Igualdad. El pulso más fuerte de la negociación se produjo por el Ministerio de Trabajo, con competencias sobre normativa laboral y las relaciones entre la patronal y los sindicatos, y reclamado por Podemos ${ }^{40}$. Esta demanda fue la que rompió definitivamente las negociaciones entre PSOE y Podemos ${ }^{41}$. Habían transcurrido apenas 80 días de negociaciones ${ }^{42}$.

El revés en la negociación generó tensiones internas en Unidas Podemos, principalmente en Izquierda Unida (IU), miembro importante de la coalición quien se planteó un voto de investidura diferente al que marcaba Podemos en la sesión de investidura. IU obtuvo seis diputados de los 42 logrados por Unidas Podemos. Su voto no era determinante, pero si se dividiera el grupo hubiera sido políticamente significativo. IU nunca estuvo de acuerdo con exigir la coalición a toda costa, sino que prefería centrarse en el programa teniendo por objetivo principal alcanzar un acuerdo y evitar la repetición de las elecciones. El clima de tensión en todo el proceso llega al Pleno de la sesión de investidura donde tiene lugar una escenificación de los desacuerdos mantenidos por las partes y se manifiesta públicamente el intercambio de puestos ministeriales. Podemos se abstiene en la primera votación, confiriendo lo que parecía un nuevo giro al proceso, pero que finalmente no se produjo, al volver a abstenerse en segunda votación. Por segunda vez, el candidato Sánchez no obtiene la confianza del Parlamento y es rechazada su designación como Presidente. Desde entonces, y según el artículo 99 de la Constitución se activa un periodo de dos meses para que haya otra candidatura con los apoyos suficientes ${ }^{43}$.

Tras el período estival se reanuda una segunda ronda de conversaciones entre ambos partidos en la que el PSOE plantea una estrategia orientada a estrechar al máximo el margen de Unidas Podemos en la negociación. El Presidente en funciones se reúne con todos los grupos parlamentarios que podían ser claves para evitar la repetición de unas elecciones generales, el PRC y el PNV, y a su vez, los números dos y tres del partido consultan con el portavoz de ERC en el Congreso.

40 Pablo Echenique, negociador de Podemos, manifestó que «en proporcionalidad estricta tendríamos que tener 5.66 ministerios sobre los 17 que hay», El País, 29 de julio de 2019.

41 A lo largo de la negociación, también se ofreció a Unidas Podemos otros posibles ministerios, como ciencia y universidades; agricultura, pesca y alimentación que incluía el Alto comisionado para el reto demográfico; turismo y deporte o cultura. También se les ofreció las competencias de cooperación internacional y Agenda 2030 o asuntos migratorios. Pero la última oferta fue la de una vicepresidencia y los tres mencionados departamentos.

42 En Alemania la CDU y el SPD estuvieron casi seis meses negociando para alcanzar un acuerdo de estabilidad gubernamental en la actual legislatura. En la Comunidad Valenciana, en Andalucía o en la Madrid varios meses.

43 El período de dos meses finalizaba el 23 de septiembre. En caso de llegar a esta fecha sin investidura, se convocarían otras elecciones generales el 10 de noviembre, como así ocurrió finalmente. 
La maniobra es muy evidente. El PSOE considera que ninguno de estos partidos se opondrá a su propuesta de pacto programático con Unidas Podemos, pudiendo confirmar la existencia de una mayoría parlamentaria y así evitar la repetición electoral. Esta táctica negociadora sitúa a Podemos en la tesitura de adoptar una decisión final. El partido que facilitaría la gobernabilidad en caso de un acuerdo PSOE-Podemos, del tipo que fuera, era el PNV. Los nacionalistas vascos, a semejanza del comportamiento en el gobierno minoritario de Aznar, condicionaban el apoyo a obtener intereses particulares sobre asuntos clave como transferencias e inversiones en la comunidad vasca ${ }^{44}$. Por tanto, se convierte una vez más en un partido con una posición determinante. La ruptura definitiva de las negociaciones entre PSOE y Podemos por sus respectivas posiciones antagónicas, por la inflexibilidad en sus posturas y por la desconfianza mutua entre los líderes, no permitió que el modelo de gobierno a la portuguesa que se había alcanzado en nuestro país vecino fuese la solución en aquel momento para el sistema político español ${ }^{45}$. La incapacidad de los partidos para pactar fuerza a una repetición electoral como única salida posible al bloqueo institucional. Pedro Sánchez, Presidente del Gobierno en funciones, afronta el reto de celebrar nuevas elecciones con la intención de obtener una victoria más amplia que facilite su investidura. La legislatura que se cierra duró 126 días, convirtiéndose en una de las más cortas de nuestra historia democrática más reciente.

A pesar de las intenciones de salir del bloqueo con unas nuevas elecciones, los resultados electorales de noviembre de 2019 no modificaron el escenario político surgido en abril. La distribución de las fuerzas políticas parlamentarias reproducía el formato de un modelo de gobierno minoritario débil o un gobierno de coalición que exigía del apoyo de formaciones políticas de ideología diversa para que el candidato del PSOE lograra ser investido por el Congreso de los Diputados. Aprendida la lección los candidatos de los partidos de la izquierda, Sánchez e Iglesias, tardaron escasos días en firmar un preacuerdo que definía las líneas programáticas que dirigirían siguientes reuniones entre los representantes de ambos partidos. Ambas formaciones suman 155 escaños. El principal escollo que se encuentra el candidato Sánchez es la necesidad de contar con el apoyo de fuerzas nacionalistas con escasa representación parlamentaria - PNV con 6 diputados, Mas País con 3 diputados, y con 1 diputado Nueva Canarias, Bloque Nacionalista Gallego y Teruel Existe, respectivamente. Y además de ello debía

44 De hecho, el PNV apoyó la moción de censura que derribó a Mariano Rajoy, con quien una semana antes había pactado los presupuestos generales del Estado, y así evitar que Ciudadanos llegara al poder.

45 En Portugal, en 2015 el Primer Ministro socialista, Antonio Costa, asegura la gobernabilidad con el apoyo de partidos con los que adoptó acuerdos bilaterales sobre políticas concretas (la denominada geringonça). Con sólo 86 escaños en el parlamento nacional, el partido de Costa fruto de intensas, hábiles y pragmáticas negociaciones suma los votos de tres formaciones más: el Bloco de Esquerda (BE), con 19 escaños; el Partido Comunista de Portugal (PCP), con 15 escaños; y el Partido Ecologista Os Verdes (PEV), con 2 escaños. Con estas fuerzas alcanza la mayoría absoluta, frente a los 108 escaños de la oposición conservadora, liderada por el Partido Social Demócrata (PSD) de Pedro Passos Coelho, que ganó las elecciones con 89 parlamentarios. 
asegurar la abstención en la investidura de Esquerra Republicana de Catalunya (ERC) que había salido fortalecida de las elecciones y la de Bildu, con 5 diputados en la cámara baja. En definitiva, Sánchez necesitaba cuadrar un complejo rompecabezas para lograr los apoyos mínimos que le aseguraran la investidura como Presidente del Gobierno en una segunda votación, en el Congreso más fragmentado de la democracia española. El acuerdo entre PSOE y ERC supone una rectificación de la estrategia desplegada por ambas formaciones políticas en años anteriores.

\section{V. ¿COMO ASEGURAR LA GOBERNABILIDAD?}

Alemania es un ejemplo ilustrativo de combinación entre estabilidad y gobernabilidad. La ausencia, en muchas ocasiones, de un partido con mayoría absoluta en el Bundestag no ha impedido la formación de gobiernos estables que han asegurado la gobernabilidad del sistema. Los grandes partidos siempre han llegado a acuerdos, instrumentados, generalmente, mediante la fórmula de gobiernos de coalición evitando los problemas derivados de la inestabilidad gubernamental. Que este tipo de medidas no haya sido posible en España tras los resultados electorales de 2015, 2016 y abril de 2019 solo puede comprenderse por la excesiva polarización ideológica y el distanciamiento existente entre los dos grandes partidos de ámbito estatal en temas relevantes y por el marco de un desafío independentista sin precedentes en el sistema político español. Si este modelo de gobierno no es posible, el acuerdo ha de entablarse entre partidos ideológicamente cercanos con los que el entendimiento pareciera menos complejo, y como así ha sido tras los resultados de las elecciones de noviembre de 2019. En este sentido Portugal es un caso de estudio en el que ha pretendido mirarse España. Un sistema político con elevadas dosis de polarización, con gobiernos en minoría y con formación de gobierno a través de mociones de censura. De forma paralela a lo acontecido en España, las elecciones portuguesas de 2015 celebradas en un contexto de crisis económica y de austeridad impuesta por la Unión Europea, dieron la victoria al Partido Social Demócrata (PSD), quien no obtiene mayoría suficiente para gobernar en solitario, lo que conduce a la formación de un gobierno frágil de centroderecha liderado por el Centro Democrático Social (CDS) con 104 escaños de los 230 que integran el Parlamento, apenas el 38,5 por ciento de los diputados, y basado en un programa de gobierno muy preciso en cuanto a medidas económicas para obtener el apoyo de otros grupos parlamentarios. Una coalición débil por el hecho de no ser suficiente para alcanzar la mayoría absoluta en Parlamento. Esta fragilidad junto con el crecimiento en las urnas del Partido Socialista -que quedó en segundo lugar con 85 escaños - ofrecía otra alternativa que se formalizó un mes después de las elecciones tras una moción de censura. Por primera vez en la historia de la III República portuguesa cabía la formación de un gobierno apoyado por todas las formaciones de izquierda: 
Partido Socialista (PS), Coligaşão Democrática Unitária (CDU) y el Bloco de Esquerda (BE). Esta iniciativa conllevaba el riesgo de polarizar la vida política y exigía superar las discrepancias previas entre los socios de gobierno. Ambos supuestos se produjeron.

El ejemplo ofrecido por la política española, en lo referente al bloqueo institucional tras las elecciones de abril de 2019, es un episodio paradigmático que muestra la inflexibilidad en las posturas negociadoras, dominadas por utilidades partidistas exacerbadas que no han culminado en el objetivo primordial de asegurar una mínima dosis de estabilidad gubernamental. Ha sido necesario una repetición electoral con unos resultados más complejos para reconsiderar la configuración de un gobierno de coalición en el ámbito estatal. El primero en nuestra historia democrática reciente, y ciertamente «atípico» dado que los partidos a la izquierda de la socialdemocracia suelen preferir quedarse al margen del ejecutivo, y apoyar desde el parlamento; o bien, participar en el gobierno con otros socios, como es el caso de Finlandia, donde actualmente gobierna una coalición socialista integrada por cuatro partidos ${ }^{46}$.

En España, sombras de duda se ciernen sobre la duración del gobierno investido por el Congreso en enero de 2020. A diferencia de lo ocurrido en Portugal, en nuestro Parlamento no existe una mayoría alternativa a la que apoya al gobierno de coalición, y la mayoría que ha permitido la investidura es frágil y poco cohesionada. Por tanto, podríamos vivir situaciones de bloqueo, pero en ningún caso el gobierno será reemplazado en una moción de censura. El gobierno de coalición formado requerirá de un doble nivel de negociación para adoptar cualquier medida. Por un lado, deberá acordar las iniciativas entre sus socios desde el Consejo de Ministros poniendo a prueba su capacidad de coordinación. Por otro lado, requerirá de negociación en el Congreso de los Diputados para alcanzar las mayorías requeridas y aprobar la legislación, sobre todo de aquellas reformas anunciadas como la laboral o la educativa, que precisan la modificación de leyes orgánicas, y por tanto un umbral de mayoría superior al de la investidura. Y, además, algunas dificultades surgirán porque alguna de las lealtades con las que ha contado el Presidente Sánchez serán más conflictivas de asegurar. A esta complejidad se añade la tensión de las demandas separatistas requeridas por ERC, un elemento que no figuraba ni en la formación del gobierno portugués ni en la del gobierno finlandés, en quienes ha primado una alta tolerancia en la negociación. El acuerdo con las fuerzas separatistas supone una gran incertidumbre que podría conducir a una etapa de inestabilidad institucional y constitucional. El hecho de que se sustente en la celebración de

46 Desde abril de 2019, el partido socialdemócrata finlandés (SDP) gobierna en coalición junto al Partido de Centro (KESK), los Verdes (VIHR), la Alianza de Izquierdas (VAS) y el Partido Popular Sueco (SFP). Este amplio ejecutivo integrado por 116 diputados de un Parlamento de 200 escaños es el resultado de una intensa negociación alcanzada en un contexto en el que por primera vez ningún partido superó el $20 \%$ de votos. Los socialdemócratas ganaron por solo un escaño y por apenas 7.000 votos al partido de ultraderecha Verdaderos Finlandeses (PS). 
una mesa de negociación sobre el futuro de Cataluña, ante el reiterado interés de los líderes de esta Comunidad por alcanzar una mayor dosis de autogobierno, podría materializarse en una reforma estatutaria que debiera ser aprobada por el Congreso de los Diputados y ser sometida a una consulta en Cataluña. Un planteamiento, además, que podría abrir un proceso de similares demandas por parte de otros socios del gobierno.

En todo caso, tras la investidura exitosa del candidato Sánchez, el primer objetivo del ejecutivo será la negociación, para su posterior aprobación, de la Ley de presupuestos generales del Estado. Le seguirán los acuerdos con el principal partido de la oposición para renovar los órganos institucionales. De todo ello, dependerá el carácter excepcional del primer gobierno de coalición en la España constitucional.

TITLE: Government Formation in Multi-party Systems: The Paradox of the Spanish Case.

ABSTRACT: Until recently Spain has been the only country in continental Europe in which none of its governments has been formed by more than one party. This feature is the result of a stable party system that has facilitated governance even to minority governments. The first coalition government invested in Parliament is the result of the profound transformation of the Spanish party system after the electoral processes beld during 2015-2019. In this work we address the exceptional nature of the Spanish case, it analyzes the negotiation process and the distribution of benefits for the achievement of government stability in minority parliamentary scenarios.

RESUMEN: España ha sido hasta recientemente el único país de la Europa continental en el que ninguno de sus gobiernos ha sido formado por más de un partido, consecuencia de un sistema de partidos estable que ha facilitado la gobernabilidad incluso a gobiernos minoritarios. El primer gobierno de coalición que sale investido del Parlamento es resultado de la profunda transformación del sistema de partidos español tras los procesos electorales de la etapa 2015-2019. En este trabajo abordamos la excepcionalidad del caso español, analizamos el proceso negociador y la distribución de beneficios para la consecución de la estabilidad gubernamental en escenarios parlamentarios minoritarios.

KeY wORDS: Governments, Coalitions, Party Systems

Palabras Clave: Gobiernos, Coaliciones, Sistema de partidos

FECHA DE RECEPCIÓN: 14.01.2020

FECHA DE ACEPTACIÓN: 19.02.2020 